\title{
PENGEMBANGAN PERANGKAT PEMBELAJARAN MODEL KOOPERATIF TIPE NHT DENGAN STRATEGI PEMECAHAN MASALAH (PROBLEM SOLVING) SISTEMATIS BAGI PESERTA DIDIK SMP DI KABUPATEN PRINGSEWU
}

\author{
Fendi Susanto ${ }^{1)}$, Indah Resti Ayuni Suri ${ }^{2)}$ \\ ${ }^{1), 2)}$ STMIK Teknokrat \\ Email: fendisusantosusanto@yahoo.co.id ${ }^{1)}$, ayuni_suri@yahoo.com ${ }^{2)}$
}

\begin{abstract}
Development of learning tools is a series of processes or activities undertaken to produce a learning device based on existing theories. The purpose of this research is to produce learning tool of NHT model with systematic problem solving strategy, product that produced in the form of Learning Implementation Plan (RPP) and Student Working Sheet (Module) on Building Material of Flat Space Room that meet valid, effective, and practical for junior high school students in Pringsewu. This development research adopted the ADDIE model developed by Dick and Carey and quantitative research methods. The ADDIE model has four stages including analysis, design, development, Implementation, and Evaluation .
\end{abstract}

Keywords: learning device, mathematics, NHT, systematic problem solving

\section{PENDAHULUAN}

Pendidikan merupakan pilar utama dalam pengembangan sumber daya manusia (SDM) dan masyarakat suatu bangsa. Dengan pendidikan diharapkan mampu menjadikan Sumber Daya Manusia (SDM) yang berkualitas. Melalui pendidikan manusia dididik agar mempunyai keahlian dan keterampilan sehingga menjadikan manusia yang terampil bekerja, kreatif, inovatif, dan produktif. Salah satu upaya untuk meningkatan kualitas pendidikan yang dilakukan saat ini adalah dengan dikeluarkannya Undangundang No. 20 Tahun 2003 tentang Sistem Pendidikan Nasional pada Bab II pasal 3 yang menyatakan bahwa.

"Pendidikan nasional berfungsi mengembangkan kemampuan dan membentuk watak serta peradaban bangsa yang bermartabat dalam rangka mencerdaskan kehidupan bangsa, bertujuan untuk berkembangnya potensi peserta didik agar menjadi manusia yang beriman dan bertakwa kepada Tuhan Yang Maha Esa, berakhlak mulia, sehat, berilmu, cakap, kreatif, mandiri dan menjadi warga negara yang demokratis serta bertanggung jawab".

Matematika salah satu mata pembelajaran yang universal. Dikatakan demikian karena matematika menjadi dasar pada ilmu-ilmu yang lain seperti fisika, kimia, dan ilmu-ilmu sosial. Matematika merupakan ratunya ilmu, karena matematika adalah bahasa ilmu deduktif, dalam hal ini sebagai ilmu eksakta, ilmu tentang pola keteraturan, ilmu tentang struktur yang terorganisasikan dengan baik dan untuk mempelajarinya tidak cukup hanya dengan hafalan dan membaca, tetapi memerlukan pemikiran dan pemahaman. Sehingga matematika sangat penting terutama 
mengembangkan keterampilan berpikir lulusan (peserta didik). Begitu berperannya matematika dalam kehidupan sehari-hari, seperti apa yang dikemukakan Ignacio, Nieto dan Barona (2006: 16), "Learning mathematics has become a necessity for an individual's full development in today's complex society". Belajar matematika sudah menjadi kebutuhan bagi kemajuan seseorang di masyarakat yang kompleks sekarang ini.

Namun demikian, tujuan pendidikan nasional khususnya pada bidang Matematika masih belum berhasil dicapai. berdasarkan hasil penilaian internasional mengenai prestasi belajar peserta didik. Balitbang (2011) melaporkan hasil survei Trends International Mathematics and Science Study (TIMSS) pada tahun 2003 Indonesia berada di peringkat 34 dari 45 negara. Walaupun rerata skor naik menjadi 411 dibanding 403 pada tahun 1999, kenaikan tersebut secara statistik tidak signifikan dan Indonesia masih berada di bawah rerata untuk wilayah ASEAN. Prestasi belajar pada TIMSS 2007 lebih memprihatinkan lagi, karena rerata skor peserta didik turun menjadi 397, jauh lebih rendah dibanding rerata skor internasional yaitu 500. Prestasi Indonesia pada TIMSS 2007 berada di peringkat 36 dari 49 negara (Balitbang, 2011). Tidak jauh berbeda, hasil TIMSS 2015 yang dipublikasikan Desember 2016 menunjukan prestasi belajar peserta didik Indonesia dalam bidang pendidikan matematika mendapat peringkat 46 dari 51 negara dengan skor 397. Walaupun secara peringkat ada peningkatan tetapi secara statistik belum signifikan. Peserta didik Indonesia menguasai soal yang bersifat rutin, komputasi sederhana, dan mengukur pengetahuan akan fakta yang berkonteks keseharian. Hal ini terjadi juga pada peserta didik SMP di
Pringsewu, di mana hasil wawancara peneliti dengan guru matematika menyebutkan bahwa kemampuan peserta didik di dalam menyelesaikan masalah matematika masih mengalami kesulitan khususnya pada materi Bangun Ruang Sisi Datar.

Kondisi ini menjadi perlu untuk dikaji. Di mana berdasarkan kurikulum pembelajaran matematika yang ditetapkan di Indonesia mengacu pada rekomendasi National Council of Teachers of Mathematics (NCTM) Tahun 2000, yaitu menjadikan pemecahan masalah sistematis (problem solving) sebagai fokus utama dalam strategi pembelajaran matematika dan merupakan kompetensi dasar peserta didik yang harus dipenuhi dalam pembelajaran sekolah (Balitbang, dalam Prabawa, 2009).

Menurut Jacobsen, Eggen dan Kauchak (2003: 20) Pemecahan masalah sistematis merupakan suatu aktivitas belajar yang paling bermakna dalam proses pembelajaran di dalam pendidikan formal dan dapat memungkinkan peserta didik menjadi analitis dalam mengambil keputusan di dalam kehidupan. Sehingga kemampuan pemecahan masalah sistematis di dalam matematika sangat diperlukan dan penting untuk di kuasai peserta didik dalam proses pembelajaran.

Selain dengan memperhatikan kemampuan pemecahan masalah secara sistematis, untuk meningkatkan keaktifan peserta didik dalam belajar diperlukan juga suatu model pembelajaran. Salah satu cara yang dapat digunakan adalah dengan menggunakan pembelajaran kooperatif di mana peserta didiknya dalam belajar membentuk kelompok-kelompok kecil (Slavin, 2009). Model pembelajaran kooperatif yang akan digunakan adalah model pembelajaran kooperatif tipe Numbered Heads Together (NHT). 
Model pembelajaran Numbered Heads Together (NHT) adalah model pembelajaran yang dapat menjadikan peserta didik untuk lebih aktif dan bertanggung jawab penuh untuk memahami materi pembelajaran baik secara kelompok maupun individual. Model pembelajaran Numbered Heads Together (NHT) menuntut peserta didik untuk terlibat didalam proses belajar mengajar di kelas. Dalam proses pembelajaran matematika biasanya digunakan bahan ajar tertentu. Tetapi hasil observasi peneliti dibeberapa sekolah di pringsewu masih menggunakan bahan ajar yang belum membuat peserta didik menjadi aktif dalam pembelajarannya. Bahan ajar yang berupa LKPD masih dalam bentuk biasa-biasa saja. Sehingga diperlukan suatu LKPD yang dapat melibatkan peserta didik berpartisipasi dalam pembelajaran, diantaranya pengembangan Rencana Pelaksanaan Pembelajaran (RPP) dan Lembar Kerja Peserta didik (LKPD), di LKPD dapat dikembangkan berupa masalah dari modul. Dengan adanya pengembangan Lembar Kerja Peserta didik (LKPD) diharapkan mampu menuntun peserta didik dalam belajar.

Menurut Mulyatiningsih (2012: 232), Numbered Heads Together (NHT) adalah metode pembelajaran berbentuk diskusi kelompok yang dilakukan dengan cara memberi nomor kepada peserta didik dan pemberian tugas untuk didiskusikan. Di dalam berdiskusi kelompok setiap peserta didik dipastikan harus dapat mengerjakan tugas yang diberikan. Pendapat lain disampaikan oleh Miftahul Huda (Anindita, Syafik dan Kurniawan 2013: 70), Numbered Heads Together (NHT) adalah suatu model pembelajaran kooperatif yang dapat memberikan kesempatan kepada peserta didik untuk saling sharing ide-ide dan mempertimbangkan jawaban yang paling tepat, meningkatkan semangat kerjasama peserta didik, dan dapat diaplikasikan untuk semua mata pembelajaran serta untuk semua tingkatkan kelas.

Dari beberapa pendapat di atas maka model pembelajaran kooperatif tipe Numbered Heads Together (NHT) adalah suatu model pembelajaran kooperatif yang merupakan pengembangan dari diskusi kelompok di mana setiap peserta didik diberi nomor dan berdiskusi bersama untuk memecahkan suatu persoalan. Berdasarkan beberapa penelitian yang dilakukan menyimpulkan bahwa penerapan pembelajaran kooperatif Numbered Head Together (NHT) dalam pembelajaran matematika dapat meningkatkan pemahaman peserta didik. Adapun Langkah-langkah model pembelajaran kooperatif tipe NHT menurut Rusman (2012: 89) adalah sebagai berikut:

a. Peserta didik dibagi dalam kelompok (4-5 orang) dan setiap peserta didik dalam setiap kelompok mendapat nomor;

b. Guru memberikan tugas dan tiaptiap kelompok disuruh untuk mengerjakannya.

c. Kelompok mendiskusikan jawaban yang benar dan memastikan bahwa setiap anggota kelompok dapat mengerjakannya;

d. Guru memanggil salah satu nomor peserta didik dan peserta didik yang nomornya dipanggil melaporkan hasil kerjasama mereka;

e. Peserta didik lain diminta memberi tanggapan, kemudian guru menunjuk nomor lain;

f. Kesimpulan.

Menurut Jonassen (2011: 55), pemecahan masalah sistematis (Problem Solving) adalah suatu proses pemecahan masalah sistematis dengan 
adanya suatu tujuan dan tahapan yang sistematis untuk memperoleh suatu keputusan yang tepat. Untuk memahami apa itu pemecahan masalah secara sistematis, kita harus memahami dahulu kata masalah. Masalah dalam matematika adalah sesuatu persoalan yang ia sendiri mampu menyelesaikannya tanpa menggunakan cara atau algoritma yang rutin. Sedangkan strategi pemecahan masalah sistematis menurut Kramers, dkk (Efriyadi, 2013: 60) adalah tindakan yang dilakukan secara rutin dalam menyelesaiakan suatu permasalahan utnuk memperoleh pengetahuan, pemahaman konsep, seta sebagai evaluasi proses pembelajaran sehingga dapat meningkatkan pemahaman peserta didik dan mampu meningkatkan aktivitas peserta didik. Sependapat dengan Wena, (2010:60) menyatakan bahwa "strategi pemecahan masalah sistematis adalah prosedur pemecahan masalah sistematis secara selangkah demi selangkah dengan menggunakan aturan tertentu".

Pemilihan model pengembangan yang baik akan menghasilkan produk yang efektif dan efisien. Ketepatan pemilihan model pengembangan akan menghasilkan produk yang tepat. Salah satu ciri ketepatan produk hasil pengembangan yaitu produk tersebut dapat diaplikasikan dengan baik dan memberi manfaat bagi para penggunanya. Hasil produk pengembangan yang baik dan tepat akan meningkatkan motivasi dan keinginan peserta didik untuk memperoleh pengetahuan lebih dalam terhadap materi yang disajikan. Salah satu model pengembangan yang sederhana dan mudah dipahami adalah model ADDIE.

\section{METODE PENELITIAN}

Penelitian ini adalah penelitian pengembangan. Berdasarkan definisi dan karakteristik yang terkandung dalam penelitian pengembangan dan dengan memperhatikan sifat khas dunia pendidikan, khususnya dunia sekolah maka produk penelitian ini berupaya menghasilkan suatu produk berupa model, media, peralatan, buku, modul, alat evaluasi dan perangkat pembelajaran, kurikulum, kebijakan sekolah, dan lain-lain. (Mulyatiningsih, 2012: 145).

Adapun subjek dalam penelitian ini adalah peserta didik kelas VIII B SMP Negeri 1 Ambarawa tahun Pelajaran 2016/2017. Sedangkan objek dalam penelitian yang akan digunakan dalam penelitian adalah bahan ajar matematika dalam bentuk Lembar Kerja Peserta Didik (LKPD) pada materi Bangun Ruang Sisi Datar (Kubus, Balok, Prisma, dan Limas) untuk peserta didik kelas VIII B SMP Semester genap.

Pengambilan sampel dilakukan dengan cara simple random sampling karena pengambilan anggota secara acak tanpa memperhatikan strata yang ada dalam populasi itu. Cara ini dilakukan bila anggota populasi dianggap homogen (Sugiyono, 2010: 120). Sedangkan untuk teknik pengumpulan data yang digunakan dalam penelitian ini adalah "one-shout case study yaitu suatu pendekatan dengan menggunakan 1 kali pengumpulan data". (Sugiyono, 2010: 110). Di mana data yang diperoleh dari hasil penelitian menggunakan tes, angket, observasi dan pengamatan langsung yang dilakukan oleh peneliti dengan pengamatan dan mencatat semua hasil penelitian secara sistematis.

Penelitian ini dilaksanakan dengan menggunakan langkah-langkah (tahap) penelitian pengembangan model 
ADDIE. ADDIE dikembangkan oleh Dick dan Carey (Mulyatiningsih, 2012: 200), merupakan singkatan yang mengacu pada proses-proses utama dari proses pengembangan, yaitu $\mathrm{A}=$ Analysis (analisis), $\mathrm{D}=$ Design (perancangan), $\mathrm{D}=$ Development (pengembangan), $\mathrm{I}=$ Implementation (penerapan/pelaksanaa), and $\mathrm{E}=$ Evaluation (Evaluasi).

Model ADDIE dikembangkan oleh Dick and Carey (1996) untuk merancang sistem pembelajaran. Model ADDIE ini menggunakan 5 tahap.

\section{HASIL PENELITIAN DAN PEMBAHASAN}

Tabel 1. Skor Hasil Validasi

\begin{tabular}{|c|c|c|}
\hline \multirow{2}{*}{} & \multicolumn{2}{|c|}{ Skor Lembar } \\
\cline { 2 - 3 } & RPP & LKPD \\
\hline Skor Rerata & 251 & $67,42 \%$ \\
\hline
\end{tabular}

Data Tabel 1 di atas maka penilaian RPP dan LKPD yang dikembangkan peneliti memperoleh penilaian yang sangat baik dan valid. Dengan demikian dapat disimpulkan RPP dan LKPD yang akan dikembangkan layak untuk diujicobakan.

Data hasil tes hasil belajar secara ringkas dapat dilihat seperti pada Tabel 2 berikut:

Tabel 2. Hasil Tes Belajar Peserta Didik

\begin{tabular}{|l|c|c|}
\hline \multirow{2}{*}{ Ketuntasan PD } & Prestasi & \begin{tabular}{c} 
Jumlah \\
\cline { 2 - 3 }
\end{tabular} \\
\cline { 2 - 3 } & $\begin{array}{c}\text { Pemecahan Masalah } \\
\text { Sistematis }\end{array}$ \\
\hline PD tuntas & 32 & 31 \\
\hline PD tidak tuntas & 2 & 3 \\
\hline Persentase & $94,11 \%$ & $91,18 \%$ \\
\hline
\end{tabular}

Dari Tabel 2 di atas maka prestasi belajar dari hasil tes belajar peserta didik yang tuntas belajar sebanyak 32 dari 34 peserta didik atau $94.11 \%$ sedangkan untuk pemecahan masalah sistematis ada 31 peserta didik yang tuntas atau $91.18 \%$.

Untuk analisis Tabel 1 di atas diperoleh rerata penilaian RPP adalah 251 dengan kriteria sangat baik, sehingga RPP yang akan dikembangkan layak untuk digunakan dalam penelitian. Sedangkan hasil validasi LKPD dapat diketahui bahwa rerata skor penilaian adalah 67,42 dengan kriteria sangat baik, jadi LKPD yang dikembangkan layak untuk diujicobakan.

Pada Tabel 2 di atas dapat diketahui bahwa ketuntasan belajar peserta didik dalam kemampuan prestasi memiliki persentase sebesar 94,11\% dengan kriteria sangat baik. Sedangkan ketuntasan hasil belajar 
untuk strategi pemecahan masalah sistematis memiliki persentase sebesar 91,18\% dengan kriteria sangat baik.

Hasil nilai di atas dapat dianalisis bahwa nilai prestasi maupun pemecahan masalah meningkat setelah menggunakan produk LKPD dan RPP yang dikembangkan. Hal ini menunjukkan bahwa produk yang dikembangkan efektif sesuai dengan pendapat Nieveen (1999) tentang kriteria keefektifan produk pengembangan.

Berdasarkan pembahasan di atas dapat disimpulkan bahwa pengembangan perangkat pembelajaran pada materi bangun ruang sisi datar dengan model NHT dengan strategi pemecahan masalah sistematis sudah memenuhi kriteri kevalidan, kepraktisan, dan keefektifan. Hasil uji coba menunjukkan bahwa kualitas produk yang dikembangkan sangat baik dan memenuhi kriteria valid, praktis, dan efektif. Dengan demikian produk yang dikembangkan dapat digunakan dalam proses pembelajaran dan dapat digunakan sebagai contoh pengembangan perangkat pembelajaran dengan pendekatan dan materi yang lain.

\section{KESIMPULAN DAN SARAN}

dan $\begin{gathered}\text { Berdasarkan hasil penelitian } \\ \text { pembahasan }\end{gathered}$ kesimpulan bahwa produk hasil pengembangan yaitu RPP dan LKPD termasuk di dalamnya instrumen tes bangun ruang sisi datar dengan model NHT dan strategi pemecahan masalah sistematis disimpulkan valid dengan skor total RPP 251 dari skor maksimal 265 dengan kriteria sangat baik dan skor LKPD 67,42 dari skor rerata maksimal 81,25 dengan kriteria sangat baik.

Saran yang dapat disampaikan dari hasil penelitian ini adalah: 1)
Perangkat pembelajaran dengan model NHT dapat dijadikan sebagai perangkat untuk melaksanakan pembelajaran matematika khususnya pada materi bangun ruang sisi datar kelas VIII yang dapat meningkatkan prestasi belajar peserta didik, 2) Penelitian ini dapat dijadikan sebagai acuan peneliti lain untuk mengembangkan perangkat pembelajaran pada materi yang berbeda.

\section{DAFTAR PUSTAKA}

Anindita, A.P., Syafik, A., dan Kurniawan, H. 2013. Eksperimentasi Pembelajaran Kooperatif Tipe Numbered Heads Together (NHT) terhadap Prestasi Belajar Peserta didik pada Pokok Bahasan Bangun Datar Segitiga Kelas VII SMP Negeri 26 Purworejo Tahun Pelajaran 2011/2012. Prosiding, Seminar Nasional. Yogyakarta: FMIPA UNY.

Anonim. 2003. Undang-undang RI Nomor 20 Tahun 2003 tentang Sistem Pendidikan Nasional. Jakarta: Depdiknas.

Balitbang. 2011. Laporan Hasil TIMSS. Kementerian Pendidikan dan Kebudayaan.

Dick, W., Carey, L., dan Carey. J.O. 1996. The systemic design of instruction. Boston: Allyn and Bacon.S.

Efriyadi, D. 2013. Pengembangan Perangkat Pembelajaran Model Kooperatif Tipe STAD dengan Strategi Pemevahan Masalah. Skripsi STKIP Pringsewu: Tidak diterbitkan

Ignacio, N., Nieto, L., dan Barona, E. 2006. The Affective Domain In 
Mathematics

Learning. International Electronic Journal of Mathematics Education. Vol. 1, No. 1, Hal. 16-32.

Jacobsen, D.A., Eggen, P., dan Kauchak, D. 2003. Methods for teaching:

Metode-metode Pengajaran Meningkatkan Belajar Siswa TK-SMA $8^{\text {th }}$.(Alih Bahasa: Achmad Fawaid dan Khoirul Anam). New Jersey: Merrill Prentice Hall.

Jonassen, D.H, . 2011. Learning to Solve Problems, a Handbook for Designing Problem Solving Learning Environments. New York: Routledge.

Mulyatiningsih, E. 2012. Riset Terapan Bidang Pendidkian dan Teknik. Yogyakarta: UNY Press

NCTM. 2000. Principles and Standard for School Mathematics. Reston, VA: NCTM.

Nieveen, N. 1999. Prototyping to reach product quality dalam Van der Akker, J., et al (Eds), Design approaches and tools in education and training. London: Kluwer Academic Publisher.
Prabawa, H.W. 2009. Peningkatan Kemampuan Penalaran dan Pemecahan Masalah Matematis Siswa SMA melalui Pembelajaran dengan Pendekatan Metakognitif. Tesis pada PPs UPI Bandung: Tidak diterbitkan.

Rusman. 2012. Model-model Pembelajaran Mengembangkan Profesional oleh Guru. Jakarta: Rajawali Pers.

Slavin, R.E. 2009. Cooperative Learning Teori, Riset dan Praktik. Terjemahan: Nurulita Yusron. Bandung: Nusa Media.

Sugiyono. 2010. Metode Penelitian Pendidikan Pendekatan Kuantitatif, Kualitatif, dan $R \& D$. Bandung: Alfabeta.

Wena, M. 2010. Strategi Pembelajaran Inovatif Kontemporer. Jakarta: PT Bumi Aksara. 